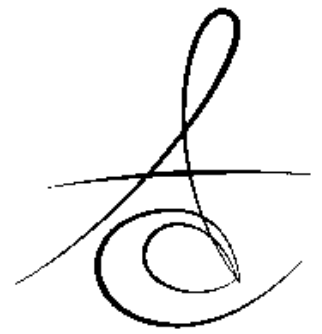

\title{
BEYAZLATICI AĞIZ GARGARALARININ KOMPOZİT REZİNİN YÜZEY PÜRÜZLÜLÜĞÜ ÜZERİNE ETKİLERİNİN İNCELENMESİ
}

\section{EFFECT OF WHITENING MOUTHRINSES ON SURFACE ROUGHNESS OF COMPOSITE RESIN}

\author{
Yrd. Doç. Dr. Çağatay BARUTCígít ${ }^{*}$ Yrd. Doç. Dr. Duygu KÜRKLÜ** \\ Arş. Gör. Dt. Kubilay BARUTCIGİL ${ }^{* * *}$ \\ Yrd. Doç. Dr. Osman Tolga HARORLI*
}

Makale Kodu/Article code: 1240

Makale Gönderilme tarihi: 22.07.2013

Kabul Tarihi: 09.09.2013

\section{ÖZET}

Amaç: Bu in-vitro çalışmanın amacı beyazlatıcı ağız gargaralarının bir nanofil kompozit rezinin yüzey pürüzlülüğü üzerine olan etkilerini incelemektir.

Gereç ve Yöntem: Altmış üç nanofil kompozit rezin örneği ( $8 \mathrm{~mm}$ x $2 \mathrm{~mm}$ ) hazırlandı ve kullanılan ağız gargarasına göre yedi gruba ayrıldı $(n=9)$; Oral-B 3D White, Crest 3D White, Colgate Optik Beyaz, Scope White, Signal White Now ve Listerine Whitening Vibrant. Kontrol grubu olarak ise distile su kullanıldı. Başlangıç yüzey pürüzlülüğü değerleri $(R a)$ bir profilometre yardımıyla ölçülüp kaydedildikten sonra her örnek $2 \mathrm{~mL}$ solüsyon içerisine konuldu ve 14 gün süresince beklenildi. Bekletilme süresinin sonunda yüzey pürüzlülüğü ölçümleri tekrarlandı ve elde edilen değerlerin istatistiksel analizleri ANOVA ve Scheffe testleri ile gerçekleştirildi $(p<.05)$.

Bulgular: Profilometerik değerlendirmeler, ağız gargaralarına maruz kalan tüm örneklerin yüzey pürüzlülüğünde küçük bir artış olduğunu göstermiştir. Ancak bu artışın ağız gargaraları ve kontrol grubu arasında istatistiksel olarak önemsiz olduğu belirlenmiştir ( $p$ > 0.05).

Sonuç: Hidrojen peroksit içeren beyazlatıcı ağız gargaralarının nanofil kompozit rezinin yüzey pürüzlülüğü üzerine olan etkilerinin göz ardı edilebilecek seviyede olduğu bu çalışmada gösterilmiştir.

Anahtar Kelimeler: Yüzey özellikleri, gargaralar, kompozit dental rezin

\section{ABSTRACT}

Objective: The aim of this in vitro study was to evaluate the effect of whitening mount rinses on superficial roughness a nanofilled resin composite.

Methods: Sixty-three nanofilled composite resin specimens ( $8 \mathrm{~mm} \times 2 \mathrm{~mm}$ ) were prepared and randomly divided into seven groups, according to the mouthrinse solutions ( $n=9$ ): Oral-B 3D White, Crest 3D White, Colgate Optik Beyaz, Scope White, Signal White Now and Listerine Whitening Vibrant. The control group used in the study was distilled water. The initial surface roughness measurements ( $\mathrm{Ra}$ ) were measured with a profilometer and then the each sample was immersed in $2 \mathrm{~mL}$ of the mouthrinses for 14 days period. After immersion period, roughness readings were repeated and the data were analyzed with ANOVA and Scheffe test $(p<.05)$.

Results: The profilometric assessment showed that exposure to mouthrinse resulted in a slightly increase in roughness values in all groups. But, the differences between mouthrinses groups and the control group were not statistically significant ( $p>0.05$ ).

Conclusion: We conclude that the influence of the whitening mouthrinses on the surface roughness of dental resin composite was negligible.

Keywords: Surface properties, mouthwashes, composite dental resins

\section{GİRİŞ}

Çeşitli sebeplerle renk değişikliğine uğramış dişlerin tedavilerinde beyazlatma, hastaların giderek artan ilgisi ile araştırmaların odağı olmaya devam etmektedir. Bu araştırmaların bir sonucu olarak da yeni beyazlatıcı ürünler piyasaya sürülmektedir. Renklenmiş dişlerin tedavisinde kullanılan hidrojen peroksit veya peroksit salabilen karbamid peroksit ya da sodyum

* Akdeniz Üniversitesi Diş Hekimliği Fakültesi Restoratif Diş Tedavisi AD, Antalya.

** Atatürk Üniversitesi Diş Hekimliği Fakültesi Protetik Diş Tedavisi AD, Erzurum.

${ }^{* * *}$ Akdeniz Üniversitesi Diş Hekimliği Fakültesi Protetik Diş Tedavisi AD, Antalya 
perborat içeren ürünler rutin diş hekimliği prosedüründe yaygın olarak farklı metotlarla kullanılmaktadır. ${ }^{1,2}$ Bununla birlikte profesyonel olarak kullanılan ürünlerin yanında reçetesiz satılan beyazlatma stripleri, macunları, jeller, gargaralar gibi diş beyazlatma ürünleri de bulunmaktadır. ${ }^{3}$ Farklı konsantrasyonlarda hidrojen peroksit, karbamid peroksit içeren bu ürünlere, bir hekim önerisi olsun veya olmasın hastalar günümüzde marketlerden, eczanelerden ve hatta internetten rahatça erişebilmektedir. Bu ürünlerden birisi de plak kontrolü ve özellikle diş eti sağlığı açısından hekimler tarafından tavsiye edilen ağız gargaralarıdır. Yapılarında su, antimikrobiyal ajanlar, tuzlar ve bazılarında da alkol ve benzeri bileşenler bulunan bilindik ağız gargaralarına son zamanlarda beyazlatıcı özelliği olduğu iddia edilen hidrojen peroksit içeren solüsyonlar da eklenmiştir. ${ }^{4}$ Değişik miktarlarda hidrojen peroksit veya benzeri kimyasallar içeren beyazlatıcı özellikteki ağız gargaraları günümüzde sıklıkla hastalar tarafından tercih edilmektedir.

Restoratif materyallerin yüzey pürüzsüzlüğü estetik görünüşün sağlanabilmesinde en önemli faktörlerden birisidir. Yüzey bütünlüğündeki düzensizlikler gingival enflamasyona ve çürük formasyonuna yola açabilen plak retansiyonu kolaylaştırır, bakteriyel adezyonu ve restoratif materyalin yüzeysel lekelenmelerini arttırır, restorasyonun parlaklığını azaltarak görüntüsünün bozulmasına ve estetik olmayan bir yapıya dönüşmesine yol açar. .,6 $^{5,6}$

Ağız gargaraları, alkol başta olmak üzere deterjanlar, emulsifiyeler, ve organik asitler gibi birçok kompozit rezinlerin yüzeysel yıkımına sebep olabilecek kimyasal madde içerebilirler. ${ }^{7}$ Gürgan ve arkadaşlarına $^{8}$ göre restoratif materyallerin yüzey sertliklerini olumsuz etkileyebilirler. Buna ilave beyazlatma tedavisinin bir sonucu olarak da beyazlatma ajanlarının sahip olduğu kimyasalların etkileri sebebiyle kompozit rezinlerin yüzey pürüzlülüğünde artış olabilir. Bazı çalışmalarda 9,10 kompozit rezin restorasyonların yüzeylerinde, ev tipi beyazlatma ajanlarının kullanıması sonucu herhangi bir pürüzlülük oluşmadığı rapor edilmesine rağmen, başka bir çalışmada da beyazlatma tedavisi sonrasında yüzeysel değişikliklerin olduğu gösterilmiştir. ${ }^{11}$

Bu çalışmanın amacı altı farklı beyazlatıcı özelliğe sahip ağız gargarasının bir nanofil kompozit rezinin yüzey pürüzlülüğüne olan etkilerini incelemektir.

\section{GEREÇ VE YÖNTEM}

Bu çalışmaya altı adet farklı içeriklere sahip beyazlatıcı özellikteki ağız gargarası dahil edildi. Bunlar, Oral-B 3D White (Procter\&Gamble $\mathrm{GmbH}$, Almanya), Crest 3D White (Procter\&Gamble $\mathrm{GmbH}$, $A B D)$, Colgate Optik Beyaz (GABA Int, İsviçre), Scope White (Procter\&Gamble $\mathrm{GmbH}, \mathrm{ABD}$ ), Signal White Now (Cosmint Spa Via, İtalya) ve Listerine Whitening Vibrant (Johnson\&Johnson, ABD). Tüm solüsyonların özellikleri ve içerikleri Tablo 1'de gösterilmektedir. Kontrol grubu olarak ise distile su kullanıldı. Ağız gargaralarının yüzey pürüzlülüğüne etkisini incelemek amaclyla bir nanofil kompozit rezin (3M Filtek Ultimate, 3M ESPE St.Paul, MN, USA) kullanıldı. Rezin kompozitten bir teflon kalıp kullanılarak $8 \mathrm{~mm}$ çapında $2 \mathrm{~mm}$ kalınlığında örnekler hazırlandı. Bir cam ve şeffaf bir polyester strip üzerine yerleştirilmiş teflon kalıp içerisine konulan kompozit rezin fazlalıkları alınıp düzeltmeleri yapıldıktan sonra üzerine başka bir polyester strip yerleştirilerek bir ışık cihazı yardımıyla (3M Freelight S10, 3M ESPE St.Paul, MN, USA) üreticisinin önerdiği süreler doğrultusunda polimerize edildi. Tüm örnekler sertleştirildikten sonra kenar düzgünlükleri ve yüzey cilalama işlemleri bir cila disk seti (3M Sof-Lex, 3M ESPE St.Paul, MN, USA) kullanılarak yapıldı. Daha sonra tüm örnekler $37{ }^{\circ} \mathrm{C}^{\prime} \mathrm{de}$ 24 saat distile su içerisinde bekletildi.

Tablo 1. Çalışmada kullanılan ağız gargaraları ve içerikleri

\begin{tabular}{|c|c|c|}
\hline Ürün & Üretici Firma & İçerik \\
\hline $\begin{array}{l}\text { Oral-B 3D } \\
\text { White }\end{array}$ & $\begin{array}{l}\text { Procter\&Gamble, } \\
\text { GmbH, GrossGerau, } \\
\text { Almanya. }\end{array}$ & $\begin{array}{l}\text { Su, Gliserin, Alkol, Aroma, } \\
\text { Metilparaben, Poloksamer 407, } \\
\text { Sodyum Florit, Setitpiridinyum Klorit, } \\
\text { Sodyum Sakarin Piropilparaben, } \\
\text { CI42051, CI47005. }\end{array}$ \\
\hline $\begin{array}{l}\text { Crest 3D } \\
\text { White }\end{array}$ & $\begin{array}{l}\text { Procter\&Gamble, } \\
\text { Cincinnati, } \mathrm{OH}, \mathrm{ABD} \text {. }\end{array}$ & $\begin{array}{l}\text { Su, Gliserin, Hidrojen Peroksit, Propilen } \\
\text { Glikol, Sodyum Heksametafosfat, } \\
\text { Poloksamer 407, Sodyum Sitrat, } \\
\text { Tatlandırıcılar, Sodyum Sakarin, Sitrik } \\
\text { Asit. }\end{array}$ \\
\hline $\begin{array}{l}\text { Colgate } \\
\text { Optik Beyaz }\end{array}$ & $\begin{array}{l}\text { GABA International } \\
\text { AG, Therwil, İsviçre. }\end{array}$ & $\begin{array}{l}\text { Su, Gliserin, Sorbitol, Piropilen Glikol, } \\
\text { PVM/MA Kopolimer, Tetrapotasyum } \\
\text { Pirofosfat, Polisorbat 20, Sodyum } \\
\text { Florit, Sodyum Sakarin, CI42051. }\end{array}$ \\
\hline Scope White & $\begin{array}{l}\text { Procter\&Gamble, } \\
\text { Cincinnati, } \mathrm{OH}, \mathrm{ABD} .\end{array}$ & $\begin{array}{l}\text { Su, Gliserin, Alkol, Hidrojen Peroksit, } \\
\text { Sodyum Heksametafosfat, Poloksamer } \\
\text { 407, Sodyum Sitrat, Tatlandırıclar, } \\
\text { Sodyum Sakarin, Sitrik Asit. }\end{array}$ \\
\hline $\begin{array}{l}\text { Signal White } \\
\text { Now }\end{array}$ & $\begin{array}{l}\text { Cosmint Spa Via, } \\
\text { Olgiate Comasco, } \\
\text { İtalya. }\end{array}$ & $\begin{array}{l}\text { Su, Sorbitol, PEG-40, Trisodyum fosfat, } \\
\text { PVM/MA Kopolimer, Sodyumlauril } \\
\text { Sülfat, Aroma, Benzil Alkol, } \\
\text { Fenoksietanol, Sodyum Florit, Sodyum } \\
\text { Sakarin, Lestin, Gliserin, Limon, } \\
\text { CI74160. }\end{array}$ \\
\hline $\begin{array}{l}\text { Listerine } \\
\text { Whitening } \\
\text { Vibrant }\end{array}$ & $\begin{array}{l}\text { Johnson\&Johnson, } \\
\text { Skillman, NJ, ABD. }\end{array}$ & $\begin{array}{l}\text { Su, Alkol, Hidrojen Peroksit, } \\
\text { Tetrapotasyum Pirofosfat, } \\
\text { Pentasodyum Trifosfat, Sitrik Asit, } \\
\text { Poloksamer 407, Tatlandırıcılar, } \\
\text { Sodyum Sakarin, Sukraloz. }\end{array}$ \\
\hline
\end{tabular}

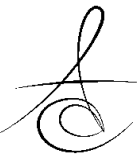


Hazırlanan kompozit örnekleri her grupta dokuz kompozit örneği olacak şekilde yedi gruba ayrıldı ve gruplardaki örneklere numara verildi. Yüzey pürüzlülük ilk değerlerinin tespit edilmesi için bir profilometre (Surtronic 25, Taylor Hobson Leicester, England) cihazı kullanıldı. Profilometre cihazı, $250 \mu \mathrm{m}$ kesme uzunluğunda (cut-off length) ve $2,5 \mathrm{~mm}$ değerlendirme uzunluğunda (evaluation length) $0,5 \mathrm{~mm} / \mathrm{s}$ hızında kullanılarak ölçümler gerçekleştirildi. Örneklerin tam ortasından olmak üzere her bir örnekten üçer ölçüm yapıldı. Her bir örnek için yüzey pürüzlülük verileri (Ra) üç ölçüm değerinin aritmetik ortala ması alınarak hesaplandı.

İlk ölçümlerden sonra örnekler 2 ml'lik hazırlanmış solüsyonlar içerisinde konuldu. Altı ağız gargarası ve distile su içerisinde örnekler 14 gün boyunca $37{ }^{\circ} \mathrm{C}^{\prime}$ de bekletildi, her gün tüm solüsyonlar yenilendi. Bekleme periyodunun sonunda tüm örnekler numaralarına göre solüsyon içerisinden çıkarıldı, distile su altında yıkandı ve son yüzey pürüzlülük ölçümleri yapıldı. Daha önce belirtilmiş olan parametreler kullanılarak ölçümler her bir örnek için tekrarlandı ve pürüzlülük değerleri (Ra) kaydedildi. Elde edilen yüzey pürüzlülük verilerinin istatistiksel değerlendirmeleri için tek yönlü varyans analizi (ANOVA), gruplar arasındaki farklııkların belirlenebilmesi için ise Scheffe çoklu karşılaştırma testi uygun bir yazılım (SPSS v20 for MAC) kullanılarak yapıldı. $\mathrm{p}<0.05$ istatistiksel anlamlılık sınır değeri olarak belirlendi.

\section{BULGULAR}

Çalışma sonucunda elde edilen tüm gruplara ait yüzey pürüzlülük değerleri $(R a)$ ve ortalama sapmaları Tablo 2'de gösterilmiştir. 14 gün sonunda yapılan ikinci yüzey pürüzlüğü ölçümlerinden sonra elde edilen verilere göre kullanılan beyazlatıcı ağız gargaralarının kompozit rezinin yüzey pürüzlülüğünü arttırdıkları ancak gargaralardaki artışların kontrol grubundaki artış ile karşılaştırıldığında istatistiksel olarak anlamlı olmadığı belirlenmiştir ( $p>0.05)$. İstatistiksel anlamlı olmamakla beraber yüzey pürüzlülüğünde en az artış 0.02 Ra ile distile su ve Crest 3D White grubunda olmuştur. Gruplar arasında en fazla yüzey pürüzlülüğünü arttıran gargaralar ise 0.14 Ra ile Signal White Now ve 0.11 Ra ile Scope White olmuştur (Şekil 1).
Tablo 2. Tüm gruplara ait yüzey pürüzlülük değerleri (Ra) ve ortalama sapmaları

\begin{tabular}{|c|c|c|c|c|c|c|c|}
\hline \multirow[t]{2}{*}{$\mathbf{R a}$} & & \multicolumn{6}{|c|}{ Ağız Gargaraları } \\
\hline & $\begin{array}{l}\text { Distil } \\
\text { e Su }\end{array}$ & $\begin{array}{c}\text { Oral-B } \\
3 \mathrm{D} \\
\text { White }\end{array}$ & $\begin{array}{c}\text { Crest } \\
3 \mathrm{D} \\
\text { White }\end{array}$ & $\begin{array}{c}\text { Colgat } \\
\mathrm{e} \\
\text { Optik } \\
\text { Beyaz }\end{array}$ & $\begin{array}{l}\text { Scope } \\
\text { White }\end{array}$ & $\begin{array}{l}\text { Signal } \\
\text { White } \\
\text { Now }\end{array}$ & $\begin{array}{c}\text { Listerin } \\
\mathrm{e} \\
\text { Whiten } \\
\text { ing } \\
\text { Vibrant }\end{array}$ \\
\hline $\mathrm{Ik}$ & $\begin{array}{c}0,25 \\
(0,14 \\
) \\
\end{array}$ & $\begin{array}{c}0,21 \\
(0,05)\end{array}$ & $\begin{array}{c}0,16 \\
(0,06)\end{array}$ & $\begin{array}{c}0,23 \\
(0,08)\end{array}$ & $\begin{array}{c}0,35 \\
(0,21)\end{array}$ & $\begin{array}{c}0,23 \\
(0,16)\end{array}$ & $\begin{array}{c}0,26 \\
(0,15)\end{array}$ \\
\hline bon & $\begin{array}{c}0,27 \\
(0,13 \\
)\end{array}$ & $\begin{array}{c}0,25 \\
(0,11)\end{array}$ & $\begin{array}{c}0,18 \\
(0,08)\end{array}$ & $\begin{array}{c}0,26 \\
(0,12)\end{array}$ & $\begin{array}{c}0,46 \\
(0,32)\end{array}$ & $\begin{array}{c}0,37 \\
(0,32)\end{array}$ & $\begin{array}{c}0,32 \\
(0,24)\end{array}$ \\
\hline
\end{tabular}

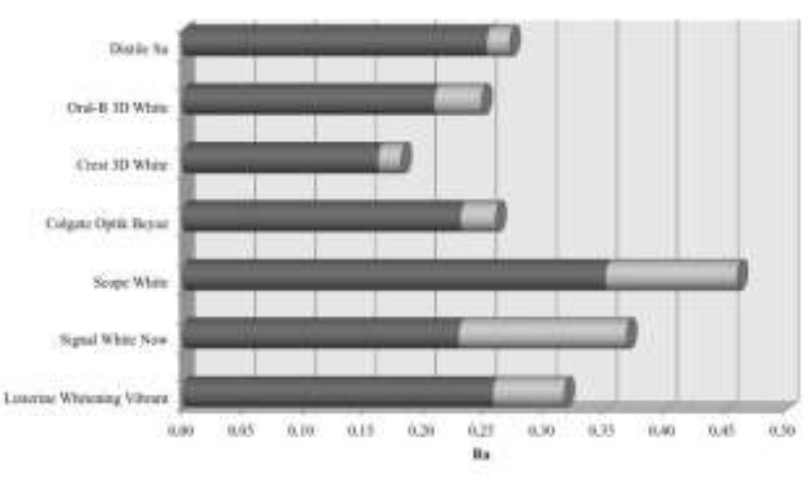

Şekil 1. Kompozit rezin örneklerinin yüzey pürüzlülük değerleri ve gargaraların etkisi ile artış miktarları (Ra)

\section{TARTIŞMA}

Bu çalışmada beyazlatıcı özellikteki ağız gargaralarının rezin kompozit yüzeyinde oluşturabilecekleri yüzey pürüzlülükleri incelenmiştir. Restorasyonlar üzerindeki yüzey pürüzlülüğü plak retansiyonu, lekelenme ve bunlarla birlikte gelen sorunlar açısından oldukça önemli bir konudur. Yapılan bir çalışmada 0.25 - 0.50 Ra aralığındaki yüzey pürüzlülüğündeki artışın hastalar tarafından fark edilebileceğini göstermiştir. ${ }^{12}$ Jones ve arkadaşları $^{12}$ restorasyon yüzeyinin maksimum 0.50 Ra yüzey pürüzlülüğünde olması gerektiğini belirtmişlerdir.

Rezin kompozit materyallerindeki çözünmeler mekanik ve kimyasal faktörlere bağlı olarak gelişebilir ve restorasyonun estetik özelliklerini bozan yüzey pürüzlülüğün artmasına ve bununla birlikte artan renklemelere yol açabilirler. ${ }^{13}$ Burada kompozit rezinin inorganik doldurucularının büyüklüğü, şekli ve miktarı, organik matriks içeriği ve kompozitin konversiyon oranı gibi faktörler kompozit rezinin degradasyonu 
konusunda belirleyicidir. ${ }^{14,15}$ Bunların yanında materyalin su emilimi de kompozit rezinin yıkımını ve bununla birlikte gelen sorunları oldukça kolaylaştırır. ${ }^{16}$

Dental rezin kompozitler söz konusu olduğunda, beyazlatma ajanları rezin matriksi, doldurucuları ya da her ikisini birlikte etkileyebilir ve materyalin çözünmesine yol açabilir. Ancak, inorganik doldurucular genellikle cam veya seramik parçacıklardan meydana geldiği için hidrojen peroksitin doldurucular üzerindeki etkisi oldukça az olmaktadır. Bunun yanında, rezin matriks hidrojen peroksitin yüksek konsantrasyonlarda veya sıklıkla uygulanmasıyla kimyasal olarak yıkıma uğrayabilir. ${ }^{17}$ Yüksek konsantrasyondaki hidrojen peroksitin restorasyonların yüzeylerinde pürüzlülük oluşturduğu yapılan çok sayıda çalışmalarla gösterilmiştir. Wang ve arkadaşları ${ }^{18} \% 35^{\prime}$ lik hidrojen peroksiti nanofil kompozit rezin üzerine uygulamışlar ve yüzey pürüzlülüğünde önemli bir artış olduğunu belirlemişlerdir. Rosentritt ve arkadaşları ${ }^{10}$ ise farklı tipteki kompozit rezinler, kompomer ve ormoser kullandıkları çalışmalarında, hidrojen peroksitin restorasyonların yenilenmesini gerektirecek kadar yüzey pürüzlülüğüne sebep olduğunu bildirmişlerdir. Yüzügüllü ve arkadaşları ${ }^{19} \% 20$ karbamit peroksit içeren beyazlatıcı ajanı 8 gün boyunca 3 farklı estetik rezin kompozit üzerinde uygulamışlar ve yüzey pürüzlülüğü açısından beyazlatma ajanın herhangi bir anlamlı fark oluşturmadığı bildirmişlerdir. Bunlara ilave olarak hidrojen peroksitin rezin kompozitler üzerine uygulandıklarında materyalin mikro sertliğinin etkilediği bildirilmiştir. ${ }^{20}$ Ancak bu sonuçlara ters olacak şekilde Wattanapayungkul ve arkadaşları $^{21}$ ise çalışmalarında kompozit rezin, kompomer, cam iyonomer ve rezin-modifiye cam iyonomer siman örnekleri hazırlanmış ve \%35'lik hidrojen peroksit etkisine bırakılmıştır. Sonuç olarak araştırmacılar, ofis tipi beyazlatmada çok sıklıkla kullanılan yüksek oksidasyon özelliğine sahip hidrojen peroksitin, materyallerin yüzey özelliklerinde herhangi bir değişiklik meydana getirmediği belirtmişlerdir. Aynı araştırmacılar başka bir çalışmalarında ${ }^{22}$ ise kompozit rezinleri günde 8 saat boyunca $\% 10^{\prime}$ luk ve $\% 15^{\prime}$ lik karbamid peroksite maruz bırakmışlarıdır. Araştırmacılar çalışmalarının sonunda, restoratif materyaller üzerinde beyazlatma ajanlarının yüzey pürüzlülüğü açısından etkilerinin maruz kalınan zamana ve kullanılan materyale bağlı olarak değiştiği rapor etmişlerdir. ${ }^{22}$
Gürbüz ve arkadaşları ${ }^{23}$ çalışmalarında $\% 6.5$ hidrojen peroksit içeren bir beyazlatma stripi kullanmışlar ve bir nanofil ve ormoser kompozit üzerindeki etkisini incelemişlerdir. Araştırmacılar 21 gün boyunca uyguladıkları beyazlatma bandının kompozit rezinlerin yüzey pürüzlüğünde istatistiksel olarak anlamsız olmasına rağmen bir artışa sebep olduğunu göstermişlerdir. Benzer şekilde, yapılan bir diğer çalışmada ise \%6.5 hidrojen peroksit içeren beyazlatma stripi uygulanmış restoratif kompozit rezinler üzerindeki yüzey pürüzlülüğün göz ardı edilebilecek seviyede olduğu gösterilmiştir. ${ }^{17} \mathrm{Bu}$ çalışmada da elde edilen veriler değerlendirildiğinde düşük konsantrasyonlarda hidrojen peroksit içeren ağız gargaralarının kompozit rezinin yüzey pürüzlülüğünde önemsiz bir artışa sebep olduğu ortaya konulmuştur.

de Andrade ve arkadaşları ${ }^{24}$ çalışmalarında iki farklı konsantrasyonda (\%16 ve \%35) hidrojen peroksit içeren aynı beyazlatıcı ajanın nanofil kompozit rezin üzerinde etkilerini incelemişlerdir. Araştırmacılar, \%35'lik hidrojen peroksit içeren grubun \%16'lık hidrojen peroksit içeren grubu oranla önemli derecede yüzey pürüzlülüğünü arttırdığını göstermişlerdir. Elde ettikleri bu sonuç doğrultusunda, hidrojen peroksit gibi beyazlatıcı ajanların kompozit rezinler üzerinde yüzey pürüzlülüğü oluşturduğu sonucuna varan çalışmalarla düşük yoğunlukta hidrojen peroksit içeren ağız gargarlarının etkilerinin incelendiği bu çalışmanın sonuçları arasındaki farkın kullanılan ajanın içeriğindeki hidrojen peroksitin konsantrasyonundan kaynaklandığı ortaya konulmuştur. Bu sonuçlara paralel olarak, Trauth ve arkadaşları ${ }^{16}$ ağız gargarlarının ve diş fırçalamanın nanofil kompozit rezin yüzeyinde oluşturduğu pürüzlülüğü incelemişler ve sadece bir gargara dışında çalışmalarındaki diğer ürünlerin yüzey pürüzlülüğünü etkilemediğini bildirmişlerdir. Bir diğer benzer çalışmada da Sadaghiani ve arkadaşları ${ }^{25}$ farklı restoratif materyaller üzerinde farklı ağız gargarlarının yüzey pürüzlülüğü açısından etkilerini incelemişler ve sonuç olarak gargaraların restoratif materyallerin yüzey pürüzlülüğünün istatistiksel olarak anlamlı olmasa dahi arttırdığını bildirmişlerdir. Miranda ve arkadaşları $^{4}$ ise hidrojen peroksit ve alkol içeren ağız gargarlarının rezin kompozitlerin yüzey pürüzlülüğünün 12 saat ve 24 saat sonra yaptıkları ölçümlerde zamana bağlı olarak arttırdığını tespit etmişlerdir. Bu çalışmada ise daha uzun bir süre etki altında kalmalarına rağmen 
kompozit rezinler yüzey pürüzlülüğü açısından ağız gargaraları tarafından önemli miktarda etkilenmemişlerdir.

Hastalar tarafından sıklıkla tercih edilen ve reçetesiz satılan beyazlatma ürünlerinden biri olan ağız gargaraları düşük konsantrasyonlarda hidrojen veya karbamit peroksit veya başka kimyasal maddeler içerebilirler. Bu çalışmada kullanılan altı farklı ağız gargarasından üç tanesi hidrojen peroksit içermesine rağmen yüzey pürüzlülüğü açısından diğer ürünlerden farklı bulunmamıştır. Bu sonuçlarda bize üreticiler tarafından beyazlatıcı özelliği olduğu iddia edilen ağız gargaralarının kompozit rezinlerin yüzeyinde hidrojen peroksit içersin veya içermesin önemli bir etkisinin olmadığını göstermektedir. Ancak yine de kullanımlarının kontrol altına alınamadığı bu ve benzeri ürünlerin uzun dönem etkileri ve yan etkilerinin tam olarak incelenebilmeleri açından daha fazla bağımsız çalışmaya ihtiyaç vardır.

\section{SONUÇ}

Bu çalışmanın sınırları içerisinde kullanılan altı farklı beyazlatıcı ağız gargarasının nanofil kompozit rezininin yüzey pürüzlülüğünde meydana getirdikleri artışın göz ardı edilebilecek seviyede olduğu gösterilmiştir.

\section{KAYNAKLAR}

1. Garcia-Godoy F, Garcia-Godoy A, Garcia-Godoy F. Effect of bleaching gels on the surface roughness, hardness, and micromorphology of composites. Gen Dent 2002;50:247-50.

2. Jefferies SR. The art and science of abrasive finishing and polishing in restorative dentistry. Dent Clin North Am 1998;42:613-27.

3. Lima FG, Rotta TA, Penso S, Meireles SS, Demarco FF. In vitro evaluation of the whitening effect of mouth rinses containing hydrogen peroxide. Braz Oral Res 2012;26:269-74.

4. Miranda Dde A, Bertoldo CE, Aguiar FH, Lima DA, Lovadino JR. Effects of mouthwashes on Knoop hardness and surface roughness of dental composites after different immersion times. Braz Oral Res 2011;25:168-73.

5. Yalcin F, Gurgan S. Effect of two different bleaching regimens on the gloss of tooth colored restorative materials. Dent Mater 2005;21:464-8.

6. Yıldırım M, Patır A, Seymen F, Gençay K. Estetik restoratif materyallerin cila işlemlerinden sonra yüzey yapısının SEM ile incelenmesi. Atatürk Üniv. Diş Hek. Fak. Derg. 2012;22:277-86.

7. Colucci V, Dos Santos CD, Do Amaral FL, Corona $\mathrm{SA}$, Catirse $\mathrm{AB}$. Influence of $\mathrm{NaHCO} 3$ powder on translucency of microfilled composite resin immersed in different mouthrinses. J Esthet Restor Dent 2009;21:242-8.

8. Gurgan $S$, Onen $A$, Koprulu $H$. In vitro effects of alcohol-containing and alcohol-free mouthrinses on microhardness of some restorative materials. J Oral Rehab 1997;24:244-46.

9. Yalcin F, Gurgan S. Bleaching-induced colour change in plastic filling materials. J Biomater Appl 2005; 19:187-95.

10. Rosentritt M, Lang R, Plein T, Behr M, Handel G. Discoloration of restorative materials after bleaching application. Quintessence Int 2005;36:33-9.

11. Belli S, Tanriverdi FF, Belli E. Colour stability of three esthetic laminate materials against to different staining agents. J Marmara Univ Dent Fac 1997;2:643-8.

12. Jones CS, Billington RW, Pearson GJ. The in vivo perception of roughness of restorations. Br Dent J 2004;196:42-5.

13. Voltarelli FR, Santos-Daroz CB, Alves MC, Cavalcanti AN, Marchi GM. Effect of chemical degradation followed by toothbrushing on the surface roughness of restorative composites. J Appl Oral Sci 2010;18:585-90.

14. Yeh ST, Wang HT, Liao HY, et al. The roughness, microhardness, and surface analysis of nanocomposites after application of topical fluoride gels. Dent Mater 2011;27:187-96.

15. Goncalves L, Filho JD, Guimaraes JG, Poskus LT, Silva EM. Solubility, salivary sorption and degree of conversion of dimethacrylate-based polymeric matrixes. J Biomed Mater Res B Appl Biomater 2008;85:320-5.

16. Trauth KG, Godoi AP, Colucci V, Corona SA, Catirse $A B$. The influence of mouthrinses and simulated toothbrushing on the surface roughness of $a$ nanofilled composite resin. Braz Oral Res 2012;26:209-14. 
17. Kim JH, Lee YK, Lim BS, Rhee SH, Yang HC. Effect of tooth-whitening strips and films on changes in color and surface roughness of resin composites. Clin Oral Investig 2004;8:118-22.

18. Wang L, Francisconi LF, Atta MT, et al. Effect of bleaching gels on surface roughness of nanofilled composite resins. Eur J Dent 2011;5:173-9.

19. Yüzügüllü $B$, Çelik Ç, Erkut $S$. Karbamid peroksit içeren beyazlatma ajanının kompozit rezinlerin yüzey pürüzlülüğüne etkisi. Atatürk Üniv. Dis Hek. Fak. Derg. 2008;18:94-8.

20. Attin T, Hannig C, Wiegand A, Attin R. Effect of bleaching on restorative materials and restorations--a systematic review. Dent Mater 2004;20:852-61.

21. Wattanapayungkul P, Yap AU. Effects of in-office bleaching products on surface finish of toothcolored restorations. Oper Dent 2003;28:15-9.

22. Wattanapayungkul P, Yap AU, Chooi KW, et al. The effect of home bleaching agents on the surface roughness of tooth-colored restoratives with time. Oper Dent 2004;29:398-403.

23. Gurbuz A, Ozkan P, Yilmaz K, Yilmaz B, Durkan R. Effect of at-home whitening strips on the surface roughness and color of a composite and an ormocer restorative material. J Prosthodont 2013;22:69-73.

24. de Andrade IC, Basting RT, Lima-Arsati YB, et al. Surface roughness evaluation and shade changes of a nanofilled resin composite after bleaching and immersion in staining solutions. Am J Dent 2011;24:245-9.

25. Sadaghiani L, Wilson MA, Wilson NH. Effect of selected mouthwashes on the surface roughness of resin modified glass-ionomer restorative materials. Dent Mater 2007;23:325-34.

\section{Yazışma Adresi:}

Yrd. Doç. Dr. Çağatay BARUTCİĠ̇

Akdeniz Üniversitesi Diş Hekimliği Fakültesi

Restoratif Diş Tedavisi Anabilim Dalı

07058/Antalya - Türkiye

Tel: $\quad 905334286233$

Faks: 902423106967

Email: cbarutcigil@akdeniz.edu.tr 